\title{
QUALIDADE NO ATENDIMENTO: UMA AVALIAÇÃO BIBLIOMÉTRICA NOS PERIÓDICOS CIENTÍFICOS NACIONAIS (1997-2013)
}

\section{QUALITY IN ASSISTANCE: A BIBLIOMETRIC EVALUATION IN NATIONAL SCIENTIFIC JOURNALS (1997-2013)}

\section{Rachel Barreto Garcia Pereira}

Bacharel em Secretariado Executivo pela Universidade Federal de Sergipe - UFS

Secretária Administrativa do DP Arquitetura e Urbanismo

E-mail: rachel4barreto@gmail.com (Brasil)

\section{Nathalia Carvalho Moreira}

Doutoranda em Administração Pública e Governo pela Fundação Getúlio Vargas - EAESP/FGV E-mail: nathaliatp@yahoo.com.br (Brasil) 


\title{
QUALIDADE NO ATENDIMENTO: UMA AVALIAÇÃO BIBLIOMÉTRICA NOS PERIÓDICOS CIENTÍFICOS NACIONAIS (1997-2013)
}

\begin{abstract}
RESUMO
O presente trabalho teve como objetivo analisar os principais conceitos utilizados na literatura sobre "Qualidade no Atendimento". Para isso, foi realizada uma investigação utilizando o método bibliométrico como forma de analisar e mensurar os artigos científicos publicados em revistas classificadas pelo Sistema Qualis da Coordenação de Aperfeiçoamento de Pessoal no Nível Superior (Capes) da área de Administração, Ciências Contábeis e Turismo dos estratos A2, B1 e B2, entre os anos de 1997 e 2013. Dentre os principais resultados, observou-se que a maior parte dos estudos foram feitos pela abordagem metodológica qualitativa e que os autores mais citados nas referências são de nacionalidade estrangeira. Por fim, concluiu-se que o tema "Qualidade no Atendimento" - apesar de sua importância - não esteve em evidência durante esses anos, tendo sido encontrados apenas 24 trabalhos. Porém, vale salientar que este tipo de estudo, a bibliometria, nos faz conhecer minuciosamente as características do tema, principais autores e abordagens teóricas e metodológicas.
\end{abstract}

Palavras-chave: Qualidade no Atendimento; Satisfação do Cliente; Bibliometria.

\section{QUALITY IN ASSISTANCE: A BIBLIOMETRIC EVALUATION IN NATIONAL SCIENTIFIC JOURNALS (1997-2013)}

\begin{abstract}
This study aimed at analyzing the main concepts used in literature about "Costumer Quality Service". Therefore, an investigation was conducted using a bibliometric method as a way to analyze and mesure the cientific articles published on qualified journals by the Graduated Qualis Personal Perfectioning Coordenation System (CAPES in Portuguese) in Administration, Account and Tourism courses on A2, B1 and B2 levels, from 1997 until 2013. Among the results, it was identified that most part of the studies were made with a qualitative approach and the most quoted authors in the project were foreign ones. Lastly, it was concluded that the "Costumer Quality Service" theme - though its importance - was not in evidence during the years, and it was observed in only 24 articles on the subject. Nevertheless, it is worth mentioning that this kind of bibliometric study, makes understanding easy in details on the theme's characteristic and its principal authors and methodological and theoretical approaches.
\end{abstract}

Keywords: Quality Service; Bibliometrics; Costumer's Satisfaction. 


\section{INTRODUÇÃO}

Atualmente, a qualidade no atendimento é uma das principais estratégias utilizadas pelas organizações, o que a faz peça crucial para sobrevivência das mesmas devido às exigências do mercado competitivo, pois está relacionada aos anseios do cliente. Com a concorrência global, as empresas buscam profissionais que sejam capacitados, dispostos a enfrentar os desafios do mercado e principalmente que saibam trabalhar em equipe com vistas ao sucesso da organização.

A qualidade é garantia de que o cliente se tornará fiel à empresa, pois a satisfação dele está no melhor pré e pós-atendimento, cumprimento de prazo de entrega e condições de preço e pagamento. De acordo com Neiva e D’Elia (2009, p. 133) “qualidade não é mais um detalhe diferenciador. Qualidade é uma questão de sobrevivência, para empresas e profissionais que querem permanecer no mercado e manter o seu nível de competitividade".

De acordo com Silva (2014), o conceito de qualidade se torna abrangente. Ele envolve não somente a satisfação em relação ao produto final, mas também todos os fatores externos (não controláveis) que influenciam as decisões das empresas pela busca da qualidade.

Conforme Passos, Nascimento, Souza e Silva (2015), do ponto de vista competitivo as empresas devem centrar seus esforços naquilo que seus clientes julgam importante, principalmente no que se refere ao serviço prestado, pois se a percepção de qualidade no atendimento do fornecedor do serviço se distinguir da percepção do cliente resultará numa possível frustração.

Nesse contexto, este estudo pretende focar em responder ao seguinte questionamento: Qual a evolução destes conceitos e quais os principais locais de publicação dos artigos do tema? Dessa forma, o presente trabalho teve como objetivo geral analisar os principais conceitos utilizados na literatura sobre qualidade no atendimento, de modo a demonstrar sua influência nos processos de atendimento e satisfação do cliente.

E como objetivos específicos foram estipulados os seguintes: a) formar um banco de dados relevante sobre o tema qualidade no atendimento ao cliente; e b) realizar uma análise bibliométrica investigando dados importantes sob o banco de dados referente à qualidade no atendimento ao cliente.

Para isso foi realizada uma pesquisa bibliográfica para fundamentar o trabalho, seguido do método bibliométrico como forma de analisar e mensurar os artigos científicos publicados em revistas científicas classificadas pelo Sistema Qualis da Coordenação de Aperfeiçoamento de Pessoal no Nível Superior (Capes) nas áreas de Administração, Ciências Contábeis e Turismo. Justifica-se esta pesquisa em virtude da importância de conhecer o perfil da produção de artigos 
científicos sobre o tema estudado a partir de outros trabalhos, podendo integrar esses conhecimentos a novos estudos, e estimulando a sua evolução. Além disso, contribuem para as organizações e para os cursos de Secretariado Executivo e afins, e identificam o patamar de entendimento destes em relação ao tema estudado.

Dessa forma, também propagam a contribuição da pesquisa a sociedade devido às exemplificações de como devemos identificar e satisfazer os requisitos dos clientes.

\section{QUALIDADE}

Para Lucinda (2010) qualidade possui um significado diferente para cada pessoa, já que as pessoas não veem serviços e/ou produtos com a mesma percepção.

De acordo com Lucinda (2010, p. 1), “qualidade está relacionada a um produto que funciona corretamente, a um preço justo e a um serviço prestado de forma a superar as expectativas de quem dela faz uso".

Para Deming (1990, p. 25) "qualidade só pode ser definida em termos de quem avalia." O autor entende que a qualidade será o que o cliente (indivíduo e/ou organização) quer. Por outro lado, Garvin (1992) definiu cinco tipos de qualidade:

a) Transcendental: a qualidade não é analisável, depende somente da experiência e limitada por não oferecer utilidade prática;

b) Baseada no produto: definida como mensurável e variável precisa, a qualidade aqui pode estar onde o custo for maior;

c) Baseada no usuário: os produtos que melhor satisfazerem as necessidades dos consumidores serão os de maior qualidade, tentando agregar as preferências individuais para melhor satisfazer;

d) Baseado na produção: a qualidade está em atender rigorosamente ao planejamento do projeto na fabricação do produto, porém seu foco está em ser eficiente, mas não eficaz;

e) Baseada no valor: a qualidade está no produto que aplique os conceitos excelência e valor, produto de bom desempenho e valor aceitável pelo mercado. 
Essas diversas definições comprovam que conforme a situação, o conceito tem modificação. A adaptação da qualidade nos dias atuais vem de acordo com o que a clientela necessita. Com isso, as empresas precisam também se adaptar a esta realidade para competir no mercado. "Qualidade é satisfazer radicalmente ao cliente, para ser agressivamente competitivo" (Ishikawa, 1997 citado por Carvalho e Paladini, 2005, p. 17).

Quando se tem qualidade nas empresas, segundo Garvin (1992) é fato que se tem baixo custo; poucos atrasos e o aumento da produtividade, o que resulta ao final um produto de qualidade e satisfação da expectativa dos clientes. "Qualidade é a composição total das características de marketing, projeto, produção e manutenção dos bens e serviços, através dos quais os produtos atenderão as expectativas" (Feigenbaum, 1954 citado por Carvalho e Paladini, 2005, p. 15).

Observa-se, assim, que há diferentes definições sobre a qualidade, o que demonstra o quanto é difícil defini-la. Porém todas as definições levam a um só propósito: a busca da melhoria da qualidade nas organizações, tanto para a parte funcional quanto para o cliente. A qualidade é algo que sempre esteve presente na história do homem, apesar de ser, atualmente, um termo muito utilizado nas organizações e na sociedade em geral (Deming, 1990).

$\mathrm{O}$ controle da qualidade era tradicionalmente relacionado à inspeção. Com o decorrer das décadas, o desenvolvimento transformou a qualidade de controle tradicional para a era moderna da qualidade, que teve início na década de 1920 e até os dias atuais busca melhorar cada vez mais (Garvin, 1992).

De acordo com Carvalho e Paladini (2005, p. 7) a evolução da qualidade passou por quatro grandes fases (ou eras), que são: inspeção, controle estatístico, garantia da qualidade e gestão da qualidade total.

$\mathrm{Na} 1^{\mathrm{a}}$ era - da inspeção - nos séculos XVIII e XIX a qualidade era centrada na fabricação artesanal dos produtos; os artesões eram responsáveis pelo processo de produção desde a criação até a entrega do cliente. Assim, a qualidade era associada ao resultado de uma habilidade pessoal (Carvalho e Paladini, 2005).

As peças eram confeccionadas em pequenas quantidades, o que facilitava a comunicação direta com os consumidores. Esse contato direto era importantíssimo, pois o consumidor explanava seus desejos e necessidades e possibilitava que os produtos atendessem satisfatoriamente o cliente (Garvin, 1992).

Segundo Juran (1993, p. 4) "as necessidades humanas pela qualidade existem desde o crepúsculo da história". Entretanto, os meios para obter essas necessidades - os processos de 
gerenciamento para a qualidade - sofreram imensas e contínuas mudanças.

Com a Revolução Industrial a produção sofreu um crescimento significativo tanto no volume quanto na complexidade. Passou de customização para padronização, isto quer dizer que, o que era feito artesanalmente foi substituído pela utilização de maquinários. Com isso, as necessidades dos clientes já não faziam parte da formação do produto e assim começou a surti a negativação sobre a qualidade (Juran, 1993).

Para que a qualidade retornasse a produção, foram introduzidas as técnicas de controle de qualidade às denominadas centrais de inspeção, as quais consistiam em função corretiva, ou seja, que produtos defeituosos não chegassem aos consumidores, a partir disto surgiu, a função de inspetor (Carvalho e Paladini, 2005).

No século XX, com o surgimento da produção em massa, houve a necessidade de se produzirem peças intercambiáveis - o que desencadeou o surgimento do ambiente industrial e a invenção das máquinas. O ritmo de produção aumentou e as peças que eram produzidas e encaixadas manualmente assim já não podiam ser mais feitas e para minimizar este empecilho foi criado um sistema racional de medidas, gabaritos e acessórios que garantiriam a produção e posicionamento correto das peças. Os locais de trabalho também sofreram mudanças para que alocassem melhor os equipamentos, então começaram a ser construídos de acordo com eles, surgindo assim às fábricas.

A $2^{\mathrm{a}}$ era - do controle estatístico - que teve início na década de 1920, com o pioneiro Walter A. Shewart, aplicando os primeiros conhecimentos do controle estatístico na empresa que trabalhava. E em 1931, expôs na obra Economic Control of Quality of Manufactured Product criações de técnicas de qualidades aplicadas na produção diária que visavam à diminuição da inspeção e o aumento da padronização e uniformidade dos produtos.

Com isso, métodos estatísticos foram introduzidos aos controles de inspeção- Controle Estatístico da Qualidade (CEQ) - como amostragens e cálculos com ênfase ainda no produto. De acordo com Samohyl (2009, p. 9) a ideia principal do CEQ é que processos de produção com menos variabilidade propiciam níveis melhores de qualidade nos resultados da produção. Então não se inspecionavam todos os produtos individualmente. Uma quantidade limitada era selecionada de forma aleatória, passando pelo $\mathrm{CEQ}$, onde a amostra desse montante representava a qualidade de todo lote.

No decorrer da Segunda Guerra Mundial (1939-1945) houve a carência de bens civis devido

Revista de Gestão e Secretariado - GeSec, São Paulo, v. 6, n. 1, p 126-149, jan./abr. 2015. 
à introdução de materiais bélicos na indústria, as quais começaram a priorizar os cumprimentos dos prazos de entrega - o que fez com que a qualidade se tornasse inferior ao esperado, tornando maior o foco no controle da qualidade. Segundo Juran $(1993$, p. 7) a qualidade sempre caiu nas épocas de escassez.

$\mathrm{Na} 3^{\mathrm{a}}$ era - garantia da qualidade - entre os anos de 1950 e 1960, vários trabalhos que ampliaram o campo de estudo e aplicação sobre qualidade foram lançados devido às atividades da Escola de Recursos Humanos, que envolviam os trabalhos de Maslow, McGregor e Heszberg. A partir disso, foram aliadas as ferramentas estatísticas e as técnicas as habilidades e técnicas gerenciais. (Juran, 1993).

A principal característica da $3^{\mathrm{a}}$ era, segundo Oliveira (2004 p. 3), que toda a empresa passa a ser responsável pela garantia da qualidade dos produtos e serviços. Isso quer dizer que todos os membros da empresa, desde o maior nível da gerência até o funcionário operacional, devem estar pessoalmente envolvidos com a qualidade.

A $4^{\mathrm{a}}$ era - gestão da qualidade total - (também denominada por outros autores como Gestão Estratégica da Qualidade iniciada na década de 1970), é a evolução das eras antecedentes até os dias atuais. Seu principal foco são as necessidades dos consumidores, tendo toda a organização mobilizada para qualidade com ênfase na liderança da alta gerência (Oliveira, 2004).

\subsection{QUALIDADE DO ATENDIMENTO AO CLIENTE}

Para que se fale sobre a qualidade no atendimento ao cliente, é necessário entendermos o que é o termo cliente. Para Rodrigues (2004, p. 39) “o cliente é uma pessoa ou uma organização beneficiária ou usuária de um produto (bem ou serviço), mediante retorno financeiro ou de outra natureza, produzido por um fornecedor”.

Na mesma linha de definição Juran (2011, p. 55) cita que "há os clientes externos, aqueles impactados pelo produto, mas não são membros da empresa”. E os clientes internos que são as pessoas que compõem o quadro funcional da empresa, que são beneficiários dos produtos e/ou serviços que são produzidos pela organização que trabalha.

Swift (2001, p. 35) afirma que "o termo cliente foi cunhado pela primeira vez no início do século XX e demorou quase cem anos para que as empresas entendessem realmente o que ele significa”. O cliente é uma peça indispensável para a formação da organização; então, ele deve ser tratado conforme sua importância e para ele são orientados os esforços na intenção de que os produtos e/ou serviços melhorem continuamente.

Revista de Gestão e Secretariado - GeSec, São Paulo, v. 6, n. 1, p 126-149, jan./abr. 2015. 
Devido à concorrência que está muito mais acirrada nos dias atuais, as empresas precisam para sobreviverem ao mercado competitivo, a cada dia, conquistar seus clientes. Para isso é necessário que elas foquem no melhor atendimento, satisfazendo suas necessidades e expectativas.

Para que as empresas correspondam com qualidade no atendimento aos clientes elas necessitam de, primeiramente, entender que necessidades dos clientes deverão ser supridas. A partir dessa premissa, Juran (2011) classificou estas como necessidades declaradas (cliente define, deseja o que quer); reais (o que realmente necessita); percebidas (está envolvido o que constitui o produto ou qualidade); culturais, (além de produtos e processos incluem o padrão cultural); e atribuíveis a usos inesperados (ligadas a um trabalho de equipe entre fornecedor e cliente para evitar o mau uso do produto).

A qualidade no atendimento pode permitir o reposicionamento estratégico da empresa, por estar voltado inteiramente ao cliente. De acordo com Dantas (2010, p. 34), "ao atender bem, a empresa terá seus lucros garantidos pela satisfação das necessidades e anseios de sua clientela, com uma consequente imagem de seriedade e solidez junto ao mercado". Para a que empresa tenha qualidade do atendimento ao cliente é necessário que seja adotado um modelo ideal de atendimento. Assim, observa-se que as empresas devem buscar sempre a qualidade do atendimento ao cliente, com vistas a obter sempre melhor vantagem em relação aos seus concorrentes.

\subsection{SECRETARIADO EXECUTIVO E ATENDIMENTO AO PÚBLICO}

De acordo com a Lei 7.377, de 30 de setembro de 1985, que regulamenta a Profissão de Secretariado Executivo, em seu Artigo 4º , são atribuições do secretário executivo:

I - planejamento, organização e direção de serviços de secretaria;

II - assistência e assessoramento direto a executivos;

III - coleta de informações para a consecução de objetivos e metas de empresas;

IV - redação de textos profissionais especializados, inclusive em idioma estrangeiro;

V - interpretação e sintetização de textos e documentos;

VI - taquigrafia de ditados, discursos, conferências, palestras de 
explanações, inclusive em idioma estrangeiro;

VII - versão e tradução em idioma estrangeiro, para atender às necessidades de comunicação da empresa;

VIII - registro e distribuição de expediente e outras tarefas correlatas;

IX - orientação da avaliação e seleção da correspondência para fins de encaminhamento a chefia;

$\mathrm{X}$ - conhecimentos protocolares.

Por lidar diretamente com os diversos níveis hierárquicos nas organizações, o Secretário Executivo atua como um agente interno de conexão entre os vários níveis organizacionais, recepcionando diversos funcionários, gerências, diretorias e trabalhadores em geral. Ademais, pode atuar com atendimento externo de clientes, fornecedores e público em geral.

Nesse contexto, o atendimento se enquadra como item dos requisitos dispostos nos tópicos I - planejamento, organização e direção de serviços de secretaria; e II - assistência e assessoramento direto a executivos; tanto nos casos em que o Secretário Executivo possui a tarefa de atendimento ao cliente, tanto nos casos em que ele é responsável por dirigir equipes de atendimento dentro das organizações.

Além disso, disciplinas de diversos cursos de graduação em Secretariado Executivo do Brasil, possuem em suas ementas, disciplinas que abordam este conteúdo e afins, para que o Secretário Executivo trabalhe esta atividade com excelência.

Guimarães (2001, citado por Sabino e Marchelli, 2009, p. 611) analisam as mudanças na atividade secretarial, discutindo a evolução da ciência no Secretariado Executivo. Nesse contexto apresenta que as atividades de atendimento ao telefone e de visitas se transformaram em "atendimento com enfoque na qualidade total a clientes externos e internos.

De acordo com Rêgo (2007), portanto, os clientes internos são pessoas de dentro da organização, o secretário executivo tem a responsabilidade de assessorar e dar suporte para a equipe com quem trabalha, identificando as expectativas e as necessidades da equipe, executando e garantindo a satisfação. Já os clientes externos são as pessoas de fora da empresa, clientes, fornecedores $-\mathrm{o}$ atendimento tem de ser o mesmo, apesar de os objetivos serem diferentes.

Dessa forma, o profissional de secretariado executivo, precisa trabalhar harmoniosamente com os clientes internos e externos, procurando não fazer distinção de qualquer espécie, demonstrando lealdade, confiabilidade e bom senso. Uma das principais qualidades é a capacidade de relacionar-se com os outros, sendo supervisores, colaboradores e visitantes (Medeiros \&

Revista de Gestão e Secretariado - GeSec, São Paulo, v. 6, n. 1, p 126-149, jan./abr. 2015. 
Hernandes, 1999, p. 17).

\section{METODOLOGIA}

De acordo com Mendonça (2009, p. 13) "na metodologia explica-se como será realizada a pesquisa. Para tanto, é necessário definir o tipo de pesquisa que será desenvolvida, bem como os métodos e técnicas de coleta e análise de dados que serão adotados".

A pesquisa está classificada, quanto ao objetivo de estudo, como exploratória, pois este tipo cria uma maior integração em relação ao estudo. Segundo Mendonça (2009, p. 13), a pesquisa exploratória visa criar maior familiaridade em relação a um fato/fenômeno/processo, investigando o estágio em que se encontram as informações já disponíveis sobre o assunto. Nesse tipo de pesquisa não é necessário elaborar hipótese.

Quanto aos meios, a pesquisa será bibliográfica. Uma pesquisa bibliográfica é fundamentada pelas fontes secundárias advindas de livros, revistas entre outros, que tem como finalidade a leitura. A pesquisa caracteriza-se como uma abordagem mista quantitativa e foi realizada pelo método da bibliometria.

Segundo Fonseca:

A pesquisa bibliográfica é feita a partir do levantamento de referências teóricas já analisadas, e publicadas por meios escritos e eletrônicos, como livros, artigos científicos, páginas de web sites. Qualquer trabalho científico inicia-se com uma pesquisa bibliográfica, que permite ao pesquisador conhecer o que já se estudou sobre o assunto. Existem, porém pesquisas científicas que se baseiam unicamente na pesquisa bibliográfica, procurando referências teóricas publicadas com o objetivo de recolher informações ou conhecimentos prévios sobre o problema a respeito do qual se procura a resposta (Fonseca, 2002, p. 32).

A bibliometria de acordo com Fonseca (1986, p. 10) é uma técnica quantitativa e estatística de medição dos índices de produção e disseminação do conhecimento científico. Seguindo a mesma linha de raciocínio, Araújo (2006, p. 12) diz que a bibliometria consiste na aplicação de técnicas estatísticas e matemáticas para descrever aspectos da literatura e de outros meios de comunicação (análise quantitativa da informação).

Souza, Silva e Araújo (2013, p. 25) afirmam que o estudo bibliométrico está sendo conceituado como o ramo da ciência que tem como objetivo a investigação das publicações 
científicas, no sentido de levantar as principais características da comunicação científica pesquisada.

Para melhor compreender o método, Ferreira (2010, p. 3) explica que a bibliometria é baseada em três leis clássicas: Lei de Lotka (frequência de autores), investigar a produtividade dos autores em distintas disciplinas; Lei Bradford (produtividade de periódicos) estima o grau de relevância de periódicos; Lei Zift (frequência de ocorrência de palavras) medição de frequência do aparecimento das palavras em vários textos.

Seguindo os conceitos acima, para obter o resultado da pesquisa bibliométrica sobre a qualidade no atendimento, foram encontrados como banco de dados apenas um número limitado a uma amostra de 24 trabalhos retirados de periódicos nacionais na classificação Qualis da Coordenação de Aperfeiçoamento de Pessoal no Nível Superior (Capes), na área de avaliação Administração, Ciências Contábeis e Turismo, com estrato A2 a B2, em um período contido entre 1997 a 2013. Este período foi delimitado por acessibilidade e para angariar um volume maior de referências. Ademais, foram considerados apenas os estrados mais importantes para conseguir extrair o "estado da arte" do tema. Também é importante lembrar que o ano de avaliação considerado dos estratos, em qual ano a pesquisa foi realizada, pois os periódicos mudam de estratos.

Foram utilizadas as seguintes palavras-chave: "qualidade no atendimento" e "satisfação do cliente", estas pesquisadas em títulos, resumos (abstracts) e palavras-chaves (keywords) para auxílio nas pesquisas, facilitando assim a busca pelas palavras que realmente interessavam ao estudo.

A partir desse filtro foi construído um banco de dados, que permitiu a verificação de algumas informações relevantes, como o número de trabalhos publicados em relação ao tema, principais autores citados, cronologia das publicações, tipo metodologia aplicada, periódico com mais trabalhos publicados, além de traçar uma demografia tanto do perfil dos autores de cada artigo do banco de dados, como também citando as Instituições do Ensino Superior (IES) e Estado com maior número de publicações referentes ao tema, podendo assim verificar e analisar qual o grau de produção nacional acerca do assunto.

Após a leitura e sistematização das informações do banco de dados, os resultados obtidos por meio dessa metodologia são apresentados a seguir, por meio de tabelas para melhor visualização. 


\section{ANÁLISE DE DADOS}

A Tabela 1 reporta-se ao banco de dados utilizado como instrumento de estudo da pesquisa, ou seja, nesta estão contidos os 24 trabalhos pesquisados nos periódicos científicos de classificação Qualis da Capes.

Tabela 1 - Artigos examinados

\begin{tabular}{|c|c|c|c|c|c|}
\hline Item & Artigo & Autor & Ano & Periódico & Estrato \\
\hline 1 & $\begin{array}{c}\text { QDF - Desdobramento } \\
\text { da função qualidade - } \\
\text { estruturando a } \\
\text { satisfação do cliente }\end{array}$ & Fábio de Souza Abreu & 1997 & $\begin{array}{c}\text { RAE - Revista de } \\
\text { Administração de } \\
\text { Empresas }\end{array}$ & A2 \\
\hline 2 & $\begin{array}{l}\text { Pesquisa de satisfação } \\
\text { de clientes: o estado- } \\
\text { da-arte e proposição de } \\
\text { um método brasileiro }\end{array}$ & $\begin{array}{l}\text { Carlos Alberto Vargas Rossi; } \\
\text { Luiz Antonio Slongo }\end{array}$ & 1998 & $\begin{array}{c}\text { RAC - Revista de } \\
\text { Administração } \\
\text { Contemporânea }\end{array}$ & A2 \\
\hline 3 & $\begin{array}{c}\text { Pesquisa: o } \\
\text { comportamento do } \\
\text { consumidor nos } \\
\text { supermercados }\end{array}$ & Francisco Jose Grandis Rojo & 1998 & $\begin{array}{c}\text { RAE - Revista de } \\
\text { Administração de } \\
\text { Empresas }\end{array}$ & A2 \\
\hline 4 & $\begin{array}{c}\text { Satisfação do cliente } \\
\text { das companhias aéreas } \\
\text { brasileiras }\end{array}$ & $\begin{array}{c}\text { Maria Cecilia Coutinho Arruda } \\
\text { Marcelo Leme de Arruda }\end{array}$ & 1998 & $\begin{array}{c}\text { RAE - Revista de } \\
\text { Administração de } \\
\text { Empresas }\end{array}$ & $A 2$ \\
\hline 5 & $\begin{array}{l}\text { O modelo do índice de } \\
\text { satisfação do cliente } \\
\text { norte-americano: um } \\
\text { exame inicial no Brasil } \\
\text { com equações } \\
\text { estruturais }\end{array}$ & $\begin{array}{c}\text { André Torres Urdan } \\
\text { Arnaldo Rocha Rodrigues }\end{array}$ & 1999 & $\begin{array}{c}\text { RAE - Revista de } \\
\text { Administração de } \\
\text { Empresas }\end{array}$ & A2 \\
\hline 6 & Custo da qualidade & Gilberto Caetano & 2001 & $\begin{array}{l}\text { Revista Administração } \\
\text { em Diálogo }\end{array}$ & B2 \\
\hline
\end{tabular}

Revista de Gestão e Secretariado - GeSec, São Paulo, v. 6, n. 1, p 126-149, jan./abr. 2015. 


\begin{tabular}{|c|c|c|c|c|c|}
\hline 7 & $\begin{array}{c}\text { A análise de } \\
\text { agrupamentos como } \\
\text { instrumento de apoio à } \\
\text { melhoria da qualidade } \\
\text { dos serviços aos } \\
\text { clientes }\end{array}$ & $\begin{array}{c}\text { Roberto Giro Moori; Reynaldo } \\
\text { Cavalheiro Marcondes; Ricardo } \\
\text { Teixeira Ávila }\end{array}$ & 2002 & $\begin{array}{c}\text { RAC - Revista de } \\
\text { Administração } \\
\text { Contemporânea (online) }\end{array}$ & A2 \\
\hline 8 & $\begin{array}{l}\text { O que o cliente de bens } \\
\text { industriais valoriza na } \\
\text { relação com os seus } \\
\text { fornecedores: o caso de } \\
\text { empresas do setor } \\
\text { metal mecânico }\end{array}$ & $\begin{array}{l}\text { Manuel Fernandes Silva Souza; } \\
\text { Roberto Giro Moori; Reynaldo } \\
\text { Cavalheiro Marcondes }\end{array}$ & 2004 & $\begin{array}{c}\text { RAC - Revista de } \\
\text { Administração } \\
\text { Contemporânea } \\
\text { (online) }\end{array}$ & A2 \\
\hline 9 & $\begin{array}{l}\text { Pesquisa de satisfação: } \\
\text { um modelo para planos } \\
\text { de saúde }\end{array}$ & $\begin{array}{c}\text { Gabriel Sperandio Milan } \\
\text { Guilherme Trez }\end{array}$ & 2005 & $\begin{array}{l}\text { RAE - Eletrônica } \\
\text { (Online) }\end{array}$ & A 2 \\
\hline 10 & $\begin{array}{l}\text { Análise do serviço de } \\
\text { atendimento ao } \\
\text { frequentador de uma } \\
\text { organização varejista à } \\
\text { luz de um marco } \\
\text { referencial de ética nos } \\
\text { negócios }\end{array}$ & $\begin{array}{l}\text { Roberto Patrus Mundim Pena } \\
\text { Álvaro Marconi Ferreira Pires }\end{array}$ & 2005 & $\begin{array}{c}\text { RAM - Revista de } \\
\text { Administração } \\
\text { Mackenzie (Online) }\end{array}$ & B1 \\
\hline 11 & $\begin{array}{c}\text { Qualidade percebida e } \\
\text { satisfação de clientes: } \\
\text { um estudo exploratório } \\
\text { sobre serviços } \\
\text { prestados por uma } \\
\text { agência de } \\
\text { comunicação }\end{array}$ & $\begin{array}{c}\text { Gabriel Sperandio Milan, } \\
\text { Juliana Brentano, Deonir de } \\
\text { Toni }\end{array}$ & 2006 & Revista Produção Online & B2 \\
\hline 12 & $\begin{array}{l}\text { Encantamento do } \\
\text { cliente: proposição de } \\
\text { uma escala para } \\
\text { mensuração do } \\
\text { constructo }\end{array}$ & $\begin{array}{l}\text { Stefânia Ordovás de Almeida; } \\
\text { Walter Meucci Nique }\end{array}$ & 2007 & $\begin{array}{l}\text { RAC-Revista de } \\
\text { Administração } \\
\text { Contemporânea }\end{array}$ & A2 \\
\hline 13 & $\begin{array}{l}\text { Determinantes da } \\
\text { Satisfação dos Clientes } \\
\text { com serviços bancários }\end{array}$ & $\begin{array}{l}\text { Kleber Fossati Figueiredo, } \\
\text { Maria Luiza Barcellos } \\
\text { Zacharias, Victor Manoel } \\
\text { Cunha de Almeida } \\
\end{array}$ & 2008 & RAE Eletrônica (Online) & A2 \\
\hline 14 & $\begin{array}{c}\text { Um estudo exploratório } \\
\text { sobre a satisfação } \\
\text { de clientes em um } \\
\text { ambiente de serviços } \\
\text { de } \\
\text { fisioterapia }\end{array}$ & Gabriel Sperandio Milan & 2008 & $\begin{array}{l}\text { Revista de Ciências da } \\
\text { Administraçãoo }\end{array}$ & B1 \\
\hline
\end{tabular}

Revista de Gestão e Secretariado - GeSec, São Paulo, v. 6, n. 1, p 126-149, jan./abr. 2015. 


\begin{tabular}{|c|c|c|c|c|c|}
\hline 15 & $\begin{array}{l}\text { O impacto da qualidade } \\
\text { percebida e da } \\
\text { satisfação na lealdade } \\
\text { dos clientes da Facilita }\end{array}$ & $\begin{array}{c}\text { Renata Guimarães Figueiredo, } \\
\text { Caroline Moreira da Silva, } \\
\text { Marlusa Gosling }\end{array}$ & 2008 & Revista Pretexto & B2 \\
\hline 16 & $\begin{array}{c}\text { Serviços médico- } \\
\text { hospitalares: Fatores de } \\
\text { satisfação dos } \\
\text { pacientes de um } \\
\text { hospital público de } \\
\text { Belém-PA }\end{array}$ & $\begin{array}{c}\text { Carlos André Corrêa de Mattos, } \\
\text { Danielle Cristina Gonzaga dos } \\
\text { Santos, Alessandro de Castro } \\
\text { Corrêa, Sérgio Castro Gomes }\end{array}$ & 2010 & Revista Pretexto & B2 \\
\hline 17 & $\begin{array}{c}\text { Proposta de um } \\
\text { instrumento de medida } \\
\text { para avaliar a } \\
\text { satisfação de clientes } \\
\text { de bancos utilizando a } \\
\text { Teoria da resposta ao } \\
\text { item }\end{array}$ & $\begin{array}{l}\text { Alceu Balbim Junior } \\
\text { Antonio Cezar Bornia }\end{array}$ & 2011 & $\begin{array}{l}\text { Revista Gestão \& } \\
\text { Produção }\end{array}$ & A2 \\
\hline 18 & $\begin{array}{c}\text { Canais de atendimento, } \\
\text { satisfação e } \\
\text { lucratividade de } \\
\text { clientes em serviços: } \\
\text { um caso bancário }\end{array}$ & $\begin{array}{c}\text { Émerson Adriano Fiebig, Ernani } \\
\text { Cesar de Freitas }\end{array}$ & 2011 & $\begin{array}{l}\text { REAd - Revista } \\
\text { Eletrônica de } \\
\text { Administração }\end{array}$ & B1 \\
\hline 19 & $\begin{array}{l}\text { Satisfação do cliente } \\
\text { como fator estratégico } \\
\text { em uma escola de } \\
\text { idiomas }\end{array}$ & $\begin{array}{c}\text { Julius Cesar Siqueira Othero } \\
\text { Fernandes; Dalton Jorge } \\
\text { Teixeira; Humberto Elias Garcia } \\
\text { Lopes }\end{array}$ & 2011 & $\begin{array}{c}\text { Revista Economia e } \\
\text { Gestão }\end{array}$ & B2 \\
\hline 20 & $\begin{array}{l}\text { Desenvolvimento e } \\
\text { validação fatorial da } \\
\text { Escala de } \\
\text { Relacionamento com } \\
\text { Clientes (ERC) }\end{array}$ & $\begin{array}{l}\text { Késia Rozzett } \\
\text { Gisela Demo }\end{array}$ & 2012 & $\begin{array}{l}\text { RAE - Revista de } \\
\text { Administração de } \\
\text { Empresas }\end{array}$ & A2 \\
\hline 21 & $\begin{array}{l}\text { A Implementação da } \\
\text { Pós-venda na empresa } \\
\text { PS Pneus em } \\
\text { Guarapuava-PR: um } \\
\text { estudo proposto pela } \\
\text { área de assessoria }\end{array}$ & $\begin{array}{c}\text { Enéia Viviane Antunes, Juliana } \\
\text { Aparecida Valus, Marcel } \\
\text { Luciano Klozovski, Juliane } \\
\text { Sachser Angnes }\end{array}$ & 2012 & $\begin{array}{c}\text { GeSec- } \\
\text { Revista de Gestão e } \\
\text { Secretariado }\end{array}$ & B2 \\
\hline 22 & $\begin{array}{c}\text { Processo de } \\
\text { investigação e análise } \\
\text { bibliométrica: avaliação } \\
\text { da qualidade dos } \\
\text { serviços bancários } \\
\end{array}$ & $\begin{array}{c}\text { Leonardo Ensslin } \\
\text { Sandra Rolim Ensslin } \\
\text { Hugo de Moraes Pinto }\end{array}$ & 2013 & $\begin{array}{l}\text { RAC. Revista de } \\
\text { Administração } \\
\text { Contemporânea }\end{array}$ & A2 \\
\hline 23 & $\begin{array}{c}\text { Satisfação no } \\
\text { atendimento: um estudo } \\
\text { na empresa JM Alarmes } \\
\text { em Guarapuava-PR }\end{array}$ & $\begin{array}{l}\text { Roseli de Oliveira Machado, } \\
\text { Juliane Sachser Angnes, } \\
\text { Marcela Elise Bordinhão } \\
\text { Pimentel, Luciano Mazur }\end{array}$ & 2013 & $\begin{array}{c}\text { GeSec- } \\
\text { Revista de Gestão e } \\
\text { Secretariado }\end{array}$ & B2 \\
\hline 24 & $\begin{array}{l}\text { Um estudo exploratório } \\
\text { sobre a satisfação } \\
\text { de clientes em um } \\
\text { ambiente de serviços de } \\
\text { fisioterapia }\end{array}$ & Gabriel Sperandio Milan & 2008 & $\begin{array}{l}\text { Revista de Ciências da } \\
\text { Administração }\end{array}$ & B1 \\
\hline
\end{tabular}

Fonte: Elaborado pelos autores (2015). 
A Tabela 1, apesar de extensa, consegue apresentar os principais dados dos artigos analisados, com título, nome completo de todos os autores, ano de publicação, nome do periódico e o respectivo estrato. Percebe-se inicialmente que apenas dois artigos foram publicados em periódicos de Secretariado Executivo (Revista GeSec), sendo que os demais artigos foram publicados em periódicos da área de Administração.

A Tabela 2 representa a quantidade de artigos publicados nos periódicos entre o período de 1997 a 2013.

Tabela 2 - Quantidade de artigos nos periódicos científicos entre 1997 a 2013.

\begin{tabular}{|c|c|c|c|}
\hline Ano & Quantidade & Ano & Quantidade \\
\hline 1997 & 1 & 2006 & 1 \\
\hline 1998 & 3 & 2007 & 4 \\
\hline 1999 & 1 & 2008 & 0 \\
\hline 2000 & 0 & 2009 & 3 \\
\hline 2001 & 1 & 2010 & 2 \\
\hline 2002 & 1 & 2011 & 2 \\
\hline 2003 & 0 & 2012 & \\
\hline 2004 & 1 & 2013 & \\
\hline 2005 & 2 & $\mathbf{2 4}$ & \\
\hline Total & \multicolumn{2}{|l}{} \\
\hline
\end{tabular}

Fonte: Elaborada pelos autores (2015).

Observa-se que o ano de maior publicação sobre o tema foi em 2008 com quatro artigos pesquisados. A Figura 1 demonstra a evolução dos números de artigos publicados por ano.

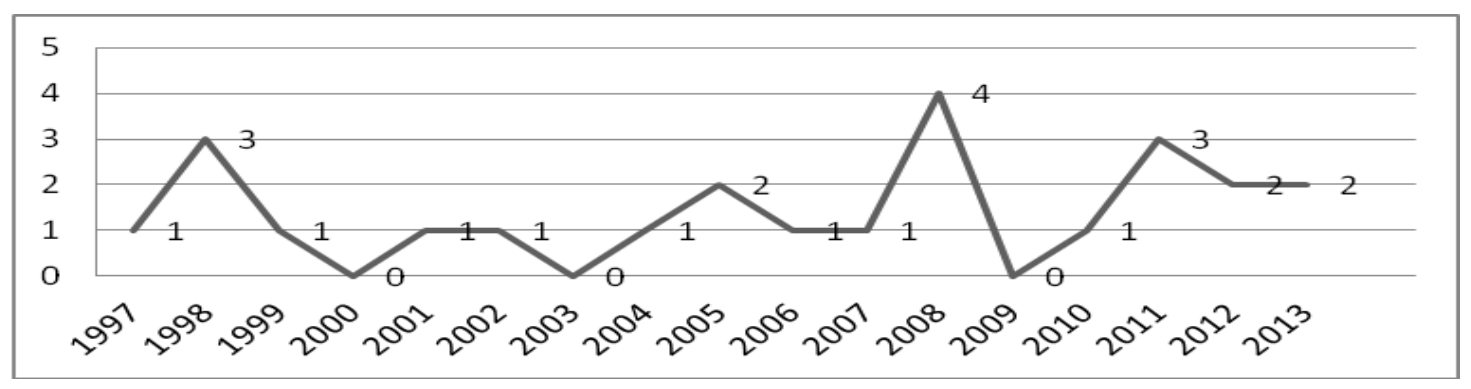

Figura 1- Evolução dos artigos publicados por ano.

Fonte: Dados da pesquisa (2015).

Revista de Gestão e Secretariado - GeSec, São Paulo, v. 6, n. 1, p 126-149, jan./abr. 2015. 
Ao analisar a Figura 1, observa-se que das publicações de artigos sobre o tema os anos 2000, 2003 e 2009, não houve de publicação, observa-se também que chegou as maiores elevações nos anos 1998, 2008 e 2011 a publicação de três e quatro artigos.

A Tabela 3 informa a quantidade de artigos publicados em cada periódico científico, complementando as informações da Tabela 2 e Figura 1.

Tabela 3 - Número de artigos por periódico.

\begin{tabular}{|c|l|l|l|l|l|l|l|l|l|l|l|l|c|c|}
\hline $\begin{array}{c}\text { Periódico*/ } \\
\text { Ano }\end{array}$ & E\&G & G\&P & GeSec & Pretexto & RAC & $\begin{array}{c}\text { RAC } \\
\text { (online) }\end{array}$ & RAD & RAE & $\begin{array}{c}\text { RAE- } \\
\text { e }\end{array}$ & RAM & RCA & Read & RPO & $\begin{array}{c}\text { Total } \\
\text { Ano }\end{array}$ \\
\hline 1997 & & & & & 1 & & & 1 & & & & & & 2 \\
\hline 1998 & & & & & 1 & & & 2 & & & & & & 3 \\
\hline 1999 & & & & & & & & 1 & & & & & & 1 \\
\hline 2000 & & & & & & & & & & & & & & 0 \\
\hline 2001 & & & & & & & 1 & & & & & & & 1 \\
\hline 2002 & & & & & & 1 & & & & & & & & 1 \\
\hline 2003 & & & & & & & & & & & & & & 0 \\
\hline 2004 & & & & & & 1 & & & & & & & & 1 \\
\hline 2005 & & & & & & & & & 1 & 1 & & & & 2 \\
\hline 2006 & & & & & & & & & & & & & 1 & 1 \\
\hline 2007 & & & & & 1 & & & & & & & & & 1 \\
\hline 2008 & & & & 1 & & & & & 1 & & 1 & & & 3 \\
\hline 2009 & & & & & & & & & & & & & & 0 \\
\hline 2010 & & & & 1 & & & & & & & & & & 1 \\
\hline 2011 & 1 & 1 & & & & & & & & & & 1 & & 3 \\
\hline 2012 & & & 1 & & & & & 1 & & & & & & 2 \\
\hline 2013 & & & 1 & & 1 & & & & & & & & 2 \\
\hline $\begin{array}{c}\text { Total } \\
\text { Periódico }\end{array}$ & 1 & 1 & 2 & 2 & 4 & 2 & 1 & 5 & 2 & 1 & 1 & 1 & 1 & $\mathbf{2 4}$ \\
\hline Total \% & $4,2 \%$ & $4,2 \%$ & $8,3 \%$ & $8,3 \%$ & $16,6 \%$ & $8,3 \%$ & $4,2 \%$ & $20.8 \%$ & $8,3 \%$ & $4,2 \%$ & $4,2 \%$ & $4,2 \%$ & $4,2 \%$ & $\mathbf{1 0 0 \%}$ \\
\hline
\end{tabular}

Fonte: Dados da pesquisa (2015).

Observa-se na Tabela 3, que a Revista de Administração de Empresas (RAE) e a Revista de Administração Contemporânea (RAC) possuem juntas 37,4\% das publicações, sobre tema, sendo que a RAE publicou 20,8\% que significa um total de cinco artigos.

Ressaltando que a $R A E$ publicou dois artigos em um mesmo ano, o de 1998, e as demais

Revista de Gestão e Secretariado - GeSec, São Paulo, v. 6, n. 1, p 126-149, jan./abr. 2015. 
publicaram juntas, mais da metade dos artigos que constam no banco de dados (62,6\%), uma média de um a dois artigos para cada uma das outras 11 revistas.

A Tabela 4 expõe o demonstrativo em relação à classificação de cada periódico científico de acordo com estrato do Sistema Qualis da Capes.

Tabela 4 - Estratos Qualis/Capes

\begin{tabular}{|c|c|c|}
\hline Estrato & Quantidade de artigos & Percentual (\%) \\
\hline A1 & 0 & $0 \%$ \\
\hline A2 & 14 & $58.4 \%$ \\
\hline B1 & 3 & $12.5 \%$ \\
\hline Total & 7 & $29.1 \%$ \\
\hline
\end{tabular}

Fonte: Elaborado pelos autores (2015).

Observa-se que, a maioria dos artigos está em revistas de estrato A2. Estando assim divididos, 14 artigos, estrato A2 seguido do B2 com sete artigos $(33,4 \%)$ e pelo B1 com três artigos $(12,5 \%)$.

Em relação ao número de autores de cada artigo pode se dizer que a característica de autoria é a publicação em conjunto como pode ser percebido na Tabela 5 a seguir.

Tabela 5 - Do número de autores.

\begin{tabular}{|c|c|c|}
\hline Número de autores & Quantidade de artigos & Percentual (\%) \\
\hline 1 & 4 & 16,6 \\
\hline 2 & 9 & 37,5 \\
\hline 3 & 8 & 33,4 \\
\hline 4 & 3 & 12,5 \\
\hline Total & 24 & $100 \%$ \\
\hline
\end{tabular}

Fonte: Elaborado pelos autores (2015).

A análise da Tabela 5 demonstra que existe predominância da publicação de artigos com dois autores, dos 24 artigos, nove foram de autoria dupla, ou seja, 37,5\%. Logo após com oito artigos $(33,4 \%)$, a publicação feita por três autores, em seguida o individual com quatro artigos $(16,6 \%)$ e por último, com três artigos, as publicações realizadas por quatro autores. Assim observase a quantidade de 58 autores. A Tabela 6 a seguir expõe o gênero dos autores dos artigos da pesquisa.

Revista de Gestão e Secretariado - GeSec, São Paulo, v. 6, n. 1, p 126-149, jan./abr. 2015. 
Tabela 6- Gênero dos autores

\begin{tabular}{|c|c|c|}
\hline Gênero & Quantidade & Percentual \\
\hline Masculino & 42 & $72,4 \%$ \\
\hline Feminino & 16 & $27,6 \%$ \\
\hline Total & 58 & $100 \%$ \\
\hline
\end{tabular}

Fonte: Elaborada pelos autores (2015).

Verifica-se que dos 58 autores, distribuídos nos 24 artigos do banco de dados, 42 são do gênero masculino $(72,4 \%)$ e 16 do gênero feminino $(27,6 \%)$, ou seja, houve a predomínio dos homens na publicação sobre o referido tema.

Sobre os tipos de metodologia aplicada, a Tabela 7 demonstra qual a predominância nos artigos.

Tabela 7- Metodologia aplicada

\begin{tabular}{|c|c|c|}
\hline Metodologia & Quantidade & Percentual \% \\
\hline Qualitativa & 12 & $50 \%$ \\
\hline Quantitativa & 5 & $20,8 \%$ \\
\hline Mista & 7 & $29,2 \%$ \\
\hline Total & 24 & $100 \%$ \\
\hline
\end{tabular}

Fonte: Elaborada pelos autores (2015).

Em relação à metodologia aplicada aos artigos, foi encontrada com maior frequência a abordagem metodológica qualitativa, em virtude de grande parte dos autores utilizarem o estudo de caso e a revisão bibliográfica.

Observa-se que a abordagem qualitativa, predomina com 50\% dos artigos, seguido do método misto com 33,3\%, o qual utiliza os métodos qualitativos e quantitativos simultaneamente, como estudo de casos com instrumentação de estatísticas descritivas, na sequência a abordagem quantitativa com $20,8 \%$ das publicações.

Os autores dos artigos existentes no banco de dados são provenientes de 16 Instituições de Ensino Superior (IES). Para análise de quantos artigos cada um das IES produziu foi feita uma distribuição na Tabela 8 abaixo.

Revista de Gestão e Secretariado - GeSec, São Paulo, v. 6, n. 1, p 126-149, jan./abr. 2015. 
Tabela 8 - Das Instituições de Ensino Superior (IES)

\begin{tabular}{|l|c|c|}
\hline \multicolumn{1}{|c|}{ Instituição de Ensino Superior (IES) } & Quantidade de artigos & Percentual \% \\
\hline $\begin{array}{l}\text { Escola de Administração de Empresas de São Paulo - } \\
\text { EAESP/FGV }\end{array}$ & 5 & $20,3 \%$ \\
\hline Universidade Federal do Rio Grande do Sul - UFRGS & 3 & $12,5 \%$ \\
\hline Universidade de São Paulo - USP & 3 & $12,5 \%$ \\
\hline Pontifícia Universidade Católica de Minas Gerais - PUC Minas & 2 & $8,3 \%$ \\
\hline Universidade Estadual do Centro-Oeste do Paraná - Unicentro & 2 & $8,3 \%$ \\
\hline Universidade Federal de Minas Gerais - UFMG & 2 & $8,3 \%$ \\
\hline Universidade Federal de Santa Catarina - UFSC & 2 & $8,3 \%$ \\
\hline Universidade Presbiteriana Mackenzie - UPM & 2 & $8,3 \%$ \\
\hline Universidade de Caxias do Sul - UCS & 2 & $8,3 \%$ \\
\hline Universidade do Vale do Rio dos Sinos - Unisinos & 1 & $4,2 \%$ \\
\hline $\begin{array}{l}\text { Pontifícia Universidade Católica do Rio Grande do Sul - PUC } \\
\text { (RS) }\end{array}$ & 1 & $4,2 \%$ \\
\hline Universidade da Amazônia - Unama & 1 & $4,2 \%$ \\
\hline Universidade Federal Rural da Amazônia - Ufra & 1 & $4,2 \%$ \\
\hline Universidade de Brasília - UnB & 1 & $4,2 \%$ \\
\hline Universidade Federal do Rio de Janeiro - UFRJ & 1 & \\
\hline
\end{tabular}

Fonte: Elaborada pelos autores (2015).

Analisando a Tabela 8 observa-se que a Escola de Administração de Empresas de São Paulo - EAESP/FGV é a que mais produziu sobre o tema do estudo, durante o período de investigação da pesquisa, seguida da Universidade Federal do Rio Grande do Sul - UFRGS e da Universidade de São Paulo - USP. A Figura 2 contém demonstrativo das quantidades de publicações de cada IES.

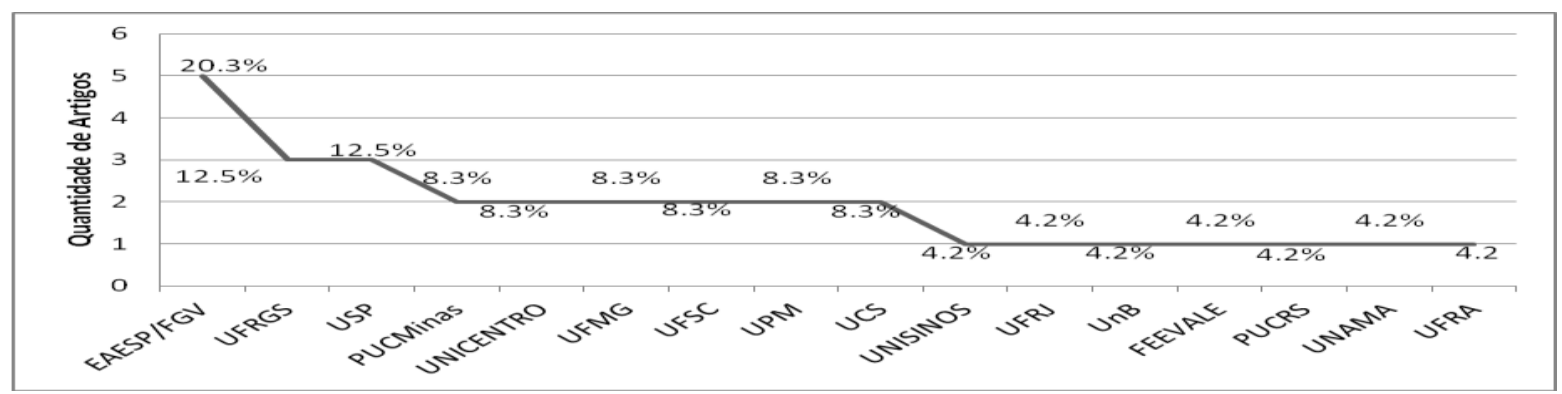

Figura 2 - Quantidade de artigos de cada IES

Fonte: Elaborado pelos autores (2015).

A Figura 2 sintetiza de modo quantificado a predominância da Escola de Administração de Empresas de São Paulo - EAESP/FGV, sobre as demais IES, com 20,3\% das publicações durante o período de 1997 a 2013.

Em relação à participação dos estados é possível verificar que as regiões Sudeste e Sul

Revista de Gestão e Secretariado - GeSec, São Paulo, v. 6, n. 1, p 126-149, jan./abr. 2015. 
possuem maior predomínio na produção de artigos sobre Qualidade no Atendimento em relação às demais regiões.

Tabela 9 - Dos Estados com maior participação

\begin{tabular}{|l|c|c|}
\hline \multicolumn{1}{|c|}{ Estados } & Quantidade de artigos & Percentual \% \\
\hline São Paulo - SP & 9 & $37,5 \%$ \\
\hline Rio Grande do Sul - RS & 5 & $20,8 \%$ \\
\hline Minas Gerais - MG & 4 & $16,6 \%$ \\
\hline Santa Catarina - SC & 3 & $12,5 \%$ \\
\hline Paraná - PR & 2 & $8,3 \%$ \\
\hline Pará - PA & 1 & $4,2 \%$ \\
\hline Rio de Janeiro - RJ & 1 & $4,2 \%$ \\
\hline Distrito Federal - DF & 1 & $4,2 \%$ \\
\hline
\end{tabular}

Fonte: Elaborado pelos autores (2015).

Em análise da Tabela 8, verifica-se que os estados de São Paulo (SP), Minas Gerais (MG) e Rio de Janeiro (RJ), juntos têm a produção de 58,3\%, isso quer dizer 14 artigos, seguidos dos estados da Região Sul, Rio Grande do Sul (RS), Santa Catarina (SC) e Paraná (PR) com 41,6\%, ou seja, 10 artigos produzidos. A Região Centro-oeste e Norte, representadas respectivamente pelo Distrito Federal (DF) e Pará (PA) tem cada um artigo produzido. Não houve nenhum representante da Região Nordeste.

Analisar a frequência de autores citados nas referências torna-se uma fonte de contribuição para outros pesquisadores, proporcionando e facilitando a busca sobre o assunto aqui pesquisado. A Tabela 9 mostra esta frequência de autores mais citados sobre qualidade no atendimento nos periódicos científicos utilizados como instrumento de busca.

Tabela 10 - Autores mais citados como referência

\begin{tabular}{|l|c|c|}
\hline \multicolumn{1}{|c|}{ Autor } & Quantidade de artigos & Percentual \% \\
\hline Zeithaml, V. A. & 12 & $50 \%$ \\
\hline Parasuraman, A. & 9 & $37,5 \%$ \\
\hline Anderson, E W. & 8 & $33,3 \%$ \\
\hline Fornell, C. & 8 & $33.3 \%$ \\
\hline Grönroos, C. & 7 & $29.1 \%$ \\
\hline Kotler, P. & 7 & $29.1 \%$ \\
\hline Juran, J. M. & 4 & $16.6 \%$ \\
\hline Las Casas, A. L. & 4 & $16.6 \%$ \\
\hline
\end{tabular}

Fonte: Elaborada pelos autores (2015).

Revista de Gestão e Secretariado - GeSec, São Paulo, v. 6, n. 1, p 126-149, jan./abr. 2015. 
Com uma análise do banco de dados (24 artigos) em relação ao item Referência, foi possível quantificar os autores mais citados.

Dos autores investigados Valarie A. Zeithaml, professor especialista em Marketing, fora citado em 12 artigos; em segundo lugar o autor A. Parasuraman foi citado em nove artigos; seguidos dos autores Eugene W Anderson e Claes Fornell com oito cada; Christian Grönroos e Phillip Kloter, com sete artigos; e Joseph Moses Juran e Alexandre L. Las Casas, com quatro artigos.

Observa-se que os autores mais citados são de nacionalidade estrangeira e apenas um autor brasileiro, Alexandre L. Las Casas, professor e consultor em Administração de Empresas na área se destaca como um dos mais citados nas referências dos trabalhos pesquisados.

Tabela 11 - Palavras-chave mais citadas

\begin{tabular}{|l|c|}
\hline \multicolumn{1}{|c|}{ Palavras-chave } & Quantidade \\
\hline Satisfação & 16 \\
\hline Qualidade & 8 \\
\hline Serviços & 7 \\
\hline Atendimento & 5 \\
\hline Relacionamento & 1 \\
\hline
\end{tabular}

Fonte: Elaborado pelos autores (2015)

A Tabela 11 contém a quantificação do uso das palavras-chave, fomentando a vertente que o tema se propôs a tratar. A palavra satisfação foi a mais citada com 16 repetições, seguida de qualidade, com oito citações. Em terceiro, a palavra serviços, com sete repetições e em quarto e quinto, respectivamente as palavras atendimento, cinco citações e apenas com uma citação a palavra relacionamento.

\section{CONSIDERAÇÕES FINAIS}

Este estudo analisou 24 artigos científicos publicados sobre a temática "Qualidade no Atendimento" em periódicos nacionais do Sistema Qualis Capes, da área de Administração, Ciências Contábeis e Turismo dos estratos A2, B1 e B2, ratificando que não constam revistas nacionais de estrato A1. Esta análise foi feita em um período que compreende o ano 1997 ao ano 2013.

Revista de Gestão e Secretariado - GeSec, São Paulo, v. 6, n. 1, p 126-149, jan./abr. 2015. 
Os resultados da pesquisa mostram que o tema investigado teve suas maiores publicações no ano 1998 com três artigos pesquisados, após uma década, no ano 2008, quatro artigos e em seguida no ano 2011 com outros três artigos. Os periódicos com mais representatividade foram a Revista de Administração de Empresas (RAE) e a Revista de Administração Contemporânea (RAC) que juntas publicaram $37,4 \%$, sobre tema, sendo a $R A E$ a mais atuante com $20,8 \%$, e a única a publicar mais de um artigo em um mesmo ano. A maior concentração de publicação encontram-se no estrato de A2, como as revistas RAE, RAC e Gestão \& Produção.

Dos artigos estudados prevalece publicação com dois autores, seguida por três autores, o que mostra que são artigos elaborados em parceria. Neste estudo foi constatada a quantidade de 58 autores, distribuídos nos gêneros masculino e feminino, como predomínio dos homens com 42 para 16 das mulheres. Ainda sobre os autores, observou que das IES que eles são provenientes, as que mais produziram foram as EAESP/FGV e UFRGS, e as regiões com maiores índices foram a Sudeste e Sul.

Constatou-se que, a maior parte dos estudos utilizou a abordagem metodológica qualitativa. E que os autores mais citados nas referências são de nacionalidade estrangeira e das palavras chaves mais citadas destacaram-se a satisfação e a qualidade.

Conclui-se a partir dos resultados obtidos durante a realização do estudo, que o tema Qualidade no Atendimento apesar de sua importância não esteve em evidência durante esses anos de pesquisas estudados. Porém vale salientar que este tipo de estudo, a bibliometria, nos faz conhecer minuciosamente as características do tema proposto. Ressalta-se que foram encontradas limitações de estudo durante a pesquisa bibliográfica, sobre a bibliometria, em relação a livros fazendo-se necessário buscar outras fontes pesquisas sobre o tema. Contudo, espera-se que esse tipo de limitação seja um estímulo para realização de estudos futuros sobre esse método de pesquisa.

Por fim, acredita-se que esta pesquisa tenha contribuído de forma prática para estudos de novos pesquisadores sobre a Qualidade no Atendimento e Secretariado Executivo.

Revista de Gestão e Secretariado - GeSec, São Paulo, v. 6, n. 1, p 126-149, jan./abr. 2015. 


\section{REFERÊNCIAS}

Araújo, C. (2006). Bibliometria: evolução histórica e questões atuais. Em Questão, Brasil, vol. 12, n. $1 . \quad$ Recuperado em $14 \quad$ agosto, 2014 de http://revistas.univerciencia.org/index.php/revistaemquestao/article/view/3707/3495.

Carvalho, M. M. de \& Paladini, E. P. (coord.) (2005). Gestão de qualidade: teoria e casos. Rio de Janeiro: Elsevier.

Dantas, E. B. (2010) Atendimento ao público nas organizações: Quando o marketing de serviços mostra a cara (3a ed.). Brasília: Senac.

Deming, W. E. (1990). Qualidade: A revelação da administração. Rio de Janeiro: Marques Saraiva.

Ferreira, A. G. C. (2010). Bibliometria na avaliação de periódicos científicos. Data Grama ZeroRevista de Ciência da Informação, vol. 11, n. 3, p. 1-9. Recuperado em 13 agosto, 2014 de http://www.dgz.org.br/jun10/Art_05.htm\#Autor.

Fonseca, E. N. (org.). (1986). Bibliometria: Teoria e prática. Textos de Paul Otlet. [et al.] São Paulo: Cultrix/ Edusp.

Fonseca, J. J. S. (2002). Metodologia da pesquisa científica. Fortaleza: UEC. [Apostila.]

Garvin, D. A. (1992). Gerenciando a qualidade: a visão estratégica e competitiva. Rio de Janeiro: Qualitymark Editora.

Juran, J. M. (1993). Juran na liderança pela qualidade: um guia para executivos. 2.ed. São Paulo: Pioneira

Juran, J. M. (2011). A Qualidade desde o projeto: novos passos para o planejamento da qualidade em produtos e serviços. São Paulo: Cenage Learning.

Lei n. 7.377, de 30 de setembro de 1985. Dispõe sobre o exercício da profissão de Secretário, e dá outras Providências. Diário Oficial da União. Brasília: Ministério da Educação e Cultura.

Lucinda, M. A. (2010). Qualidade: fundamentos e práticas para cursos de graduação. Rio de Janeiro: Brasport.

Medeiros, J. B. \& Hernandes, S. (1999). Manual da secretária: Técnicas de trabalho. São Paulo: Atlas.

Mendonça, G. M. (2009). Manual de normalização para apresentação de trabalho acadêmicos. Salvador: UNIFACS.

Neiva, E. G. \& D’Elia, M. E. S. (2009). As novas competências do profissional de secretariado (3a ed.). São Paulo: IOB.

Oliveira, O. J. (org.) (2004). Gestão da Qualidade: Tópicos Avançados. São Paulo: Pioneira.

Revista de Gestão e Secretariado - GeSec, São Paulo, v. 6, n. 1, p 126-149, jan./abr. 2015. 
Passos, N. C. H. B.; Nascimento, J. C. H. B. do; Sousa, W. D. de; Bernardez, J. R.; Silva, F. C. B. da; et al. (2015). Qualidade no Atendimento: Um estudo empírico sobre a diferença de percepção entre os públicos internos e externos. Revista Opara: Ciências Contemporâneas Aplicadas, vol. 5, n. 1.

Rêgo, C. C. A. B. (2007). Secretário executivo: o que você pode fazer de valioso para ser cobiçado pelo mercado de trabalho? Recuperado em 2 março, 2015 de: <http://www.artigos.com/artigos/artigos-academicos/educacao/secretario-executivo:-o-que-vocepode-fazer-de-valioso-para-ser-cobicado-pelo-mercado-de-trabalho?-1302/artigo/\#.VWdyitzFw0>

Rodrigues, M. V. C. (2004). Ações para a Qualidade: GEIQ gestão integrada para qualidade: padrão seis sigma - classe mundial. Rio de Janeiro: Qualitymark.

Sabino, R. F. \& Marchelli, P. S. (2009). O debate teórico-metodológico no campo do secretariado: pluralismos e singularidades. Cad. Ebape.BR, Rio de Janeiro, vol. 7, n. 4. Recuperado em 2 março, 2015 de : <http://www.scielo.br/scielo.php?script=sci_arttext\&pid=S1679$39512009000400006 \& \operatorname{lng}=$ en\&nrm=iso>.

Samohyl, R. W. (2009). Controle Estatístico de Qualidade. Rio de Janeiro: Elsevier.

Silva, M. R. L. (2014). O impacto da cultura local na qualidade do atendimento ao cliente. 2014. 21 f. Trabalho de Conclusão de Curso (Graduação em Administração) Centro de Ciências Exatas e Sociais Aplicadas, Universidade Estadual da Paraíba.

Souza, F. V., Da Silva, M. \& Araújo, A. (2013). Uma análise da produção científica da área de contabilidade governamental nos periódicos que utilizam o SEER e o SCIELO. Revista de Contabilidade da UFBA. Recuperado em 13 agosto, 2014 de http://www.portalseer.ufba.br/index.php/rcontabilidade/article/view/6268/6450.

Swift, R. (2001). CRM, customer relationship management: o revolucionário marketing de relacionamento com o cliente ( ${ }^{\mathrm{a}}$ reimpressão). Rio de Janeiro: Elsevier.

Revista de Gestão e Secretariado - GeSec, São Paulo, v. 6, n. 1, p 126-149, jan./abr. 2015. 